\title{
Process control for thermal-spray deposition of thermoset coatings using computer simulation
}

\author{
$\mathrm{Hu} \mathrm{Xu}^{1}$, Yuqing Bao ${ }^{1}$, David T. Gawne ${ }^{1}$, Tao Zhang ${ }^{2}$ \\ ${ }^{1}$ School of Engineering, London South Bank University, London, SE1 0AA, U.K. \\ ${ }^{2}$ Faculty of Science, Engineering and Computing, Kingston University, London, SW15 3DW, U.K.
}

\begin{abstract}
Thermal spraying is a green solvent-free process with the potential of applying polymer coatings to large components in-house or on-site without the need for prolonged drying. Almost no systematic research has been undertaken on thermally spraying thermoset coatings owing to the complexity and difficulty of managing the curing process. An adequately cured thermoset coating could not be deposited by thermal spraying owing to insufficient cumulative time above the cure temperature. Preheating and post-heating the substrate under a constant heat source were not successful as they led to non-uniform curing, residual stress and the risk of overheating. This study develops and validates a computer model that simulates the deposition of thermoset coatings on metal substrates using thermal spraying and high-energy infrared irradiation. The model uses readily-available commercial software and enables precise control of the coating process to improve energy efficiency and coating quality. Further research showed that evenly cured coatings could be achieved by using variable heat fluxes and controlled utilization of inward conduction from the outer surface layers. Self curing during cooling was significant and may be employed to increase energy efficiency. The thickness of the metal substrate was shown to be an important variable as it acts as a heat sink and, for heavy sections, can substantially increase energy consumption. The results indicate a need for sufficiently accurate process control and provide a suitable methodology for the deposition of thermoset coatings.
\end{abstract}

Key words: Thermal spraying, polymer coating, computer simulation, process control. 


\section{INTRODUCTION}

Polymer coatings are applied to engineering components mainly by painting, electrostatic spraying or fluidized bed dipping. Although these processes have been successful over the years, there is no one individual process that has all of the following attributes: free from environmental emissions, enabling deposition on large components in-house or structures onsite, no need for prolonged drying and avoiding variable coating quality. Thermal-spray deposition has the potential to address these collective deficiencies.

Thermal spraying is a generic family of coating processes in which the coating material, usually in the form of a powder, is injected into a hot jet or flame, where it is melted, accelerated and projected onto a substrate to form a coating. Combustion flame spraying, plasma spraying and high-velocity oxy-fuel spraying are typical thermal-spray processes. The behaviour of metallic and ceramic particles during thermal spraying is well documented but far less attention has been given to polymers.

The use of polymers in thermal spraying is gradually increasing but relates almost exclusively to thermoplastics and very little work has been undertaken on thermoset polymers. However, thermoset coatings provide a much superior performance to that of thermoplastics in terms of barrier properties, corrosion resistance, abrasion resistance and adhesion [1-4]. This is the underlying reason why over $95 \%$ of the powder coatings market consists of thermosets. The property level of thermoplastics could be raised by increasing their molecular weight but this inevitably raises their viscosity to the detriment of porosity and adhesion in the coatings. This deleterious rise in viscosity could, in turn, be overcome by increasing the processing temperatures but, in practice, it would be impracticable due to the risk of degradation and evolution of hazardous gases.

Despite its considerable potential, thermal spraying of polymer coatings remains a relatively minor activity. An important reason for this is that the process has only been successfully used for neat thermoplastics [5-12] e.g. polyamide, polyethylene, PMMA, vinyl chloride copolymers or thermoplastic composites [13-15]. Although thermoset coatings are much more important economically than thermoplastic coatings, little work has been undertaken on their deposition by thermal spraying. This is largely because the formation of thermoset coatings is much more complex and demanding than that of thermoplastics. Thermoplastic deposition only requires the particles to melt in the flame without degradation [16], flow on impact with the substrate and then bond with the substrate and surrounding splats to form a continuous, aggregate coating.

Thermosets, however, have the additional requirement of cross-linking or curing and this further complexity is responsible for the lack of successful work undertaken on thermally sprayed thermoset coatings. As well as melting without degradation, thermoset particles must not crosslink in the flame, but must flow into splats, bond to form a coherent deposit and then cross-link to produce a fully cured coating (cross-linking in the flame greatly increases the viscosity of the particles and prevents adequate flow on the substrate). In electrostatic spraying, the control of crosslinking in an oven is relatively easy since the oven treatment is essentially isothermal and curing can be controlled by fixing both the temperature and time (most commercial powders in powder-coating processes are cured at 160 to $220^{\circ} \mathrm{C}$ for 5 to 20 minutes). The thermal characteristics of flame spraying, on the other hand, are much more complex. The flame sweeps across and down the substrate surface depositing one or more layers until the required thickness of coating is built up. The hot gas jet from the spray gun impinges on and flows out laterally over the substrate or underlying layers of coating $[17,18]$. 
This imparts significant thermal energy into the coating, which can have a substantial effect on its properties, particularly for polymeric materials. Further research [19] showed that the temperature of a polymer coating during thermal spraying varies widely: for example, from $100^{\circ} \mathrm{C}$ to $180^{\circ} \mathrm{C}$ in just one sweep of the flame across the width of the substrate. This is expected to have a major influence on the curing of thermosets.

The thermal behaviour of a polymer is distinctly different from that of metals and ceramics because of its much lower melting and decomposition temperatures together with substantially lower thermal conductivities, wider liquid ranges and higher melting viscosities. The greater sensitivity of polymers to temperature compared with most metals and ceramics implies that the process window will need to be much narrower and, importantly, this will require more precise process control than that used in the spraying of metals and ceramics.

The interaction between the heat source, deposit and substrate during thermal spraying has a significant effect on the quality of the final coatings and hence has attracted widespread attention for research on process control. For example, Xia et al [20] have experimentally investigated the effect of processing parameters on the temperature profile in the coating and substrate during thermal spraying. This interaction was considered by the latter authors to be particularly important when temperature-sensitive materials, such as hydroxyapatites, were used as coating materials [21]. Sufficiently heating without overheating the surface is also likely to be a challenge for the thermal-spray deposition of thermosets [16]: the requirement is heating to a temperature that provides production-efficient crosslinking but avoids polymer degradation and the risk of the evolution of noxious gases. The very low thermal conductivity of polymers (e.g. $0.19 \mathrm{Wm}^{-1} \mathrm{~K}^{-1}$ for epoxy compared with $51.9 \mathrm{Wm}^{-1} \mathrm{~K}^{-1}$ for plain carbon steel) is likely to exert a major influence on heat flow away from the surface and its effect on overheating will be investigated in this paper.

The primary heat source in thermal spraying is the hot jet (combustion flame or plasma jet) into which the feedstock powder is injected. However, the temperature profile created on the surface of and within the depositing polymer coating is highly variable so that precise control is challenging. The use of high-energy infrared radiation either during or after deposition has potential in this regard and will form part of this study.

Producing high-quality thermoset coatings needs close control of the temperature profile in the coating and the substrate. This requires knowledge of the interaction between the applied heat sources and the coating/substrate. Experimental work can be used to provide this knowledge but is time consuming and expensive. Computer simulation has the ability to generate detailed information which, in conjunction with limited experimental work, can develop a framework for process control much more efficiently. This paper will use wellknown commercial software that is readily available for industrial users to determine the effect of critical process parameters on temperature profiles and curing.

\section{EXPERIMENTAL DETAILS}

The coating materials used for the thermal spray deposition trials in this study were epoxy (Interpon PZ) and polyester (Interpon D1063) powders supplied by Akzo Nobel (Gateshead, UK). Plain carbon steel plates of $150 \mathrm{~mm} \times 100 \mathrm{~mm}$ with varying thickness were used as substrates. The materials properties and required curing schedule at $200^{\circ} \mathrm{C}$ are given in Table I.

The coatings were deposited by combustion flame spraying with acetylene as a fuel gas, compressed air as a source of oxygen, cooling and carrier gases. The spray torch was 
mounted on a robotic traverse unit. Figure 1 shows the movement of the torch to perform a complete scan of the substrate as needed during pre-heating, the coating deposition and postdeposition heating of the coating. The arrows represents the direction of movement of the torch and show the gaps and overlaps that ensure that the workpiece is fully coated. The second scan can be applied using the same route and so on for multi-scans. Control parameters include scanning speed, step distance and number of complete scans of the substrate.

The thermal history of the coating and substrate was measured in-situ using thermocouples and infrared pyrometers during the entire process including preheating, deposition and postheating of the coatings. The information obtained is important for the control of the process parameters aimed at achieving sufficient crosslinking without degradation of thermosetting polymers. The coating surface temperature was monitored remotely using Raytek ${ }^{\circledR}$ IR thermometers. The coating-substrate interface temperature was measured using thermocouples (K type) with an 8 channels Pico ${ }^{\circledR}$ data TC-08 data loggers. Figure 2 shows the positional coordinates of thermocouples on a $150 \mathrm{~mm}$ x $100 \mathrm{~mm}$ substrate under deposition.

\section{DEVELOPING THE SIMULATIVE MODEL}

\subsection{Heat Transfer Analysis}

The properties of thermosets during thermal spraying are highly sensitive to temperature and so a heat transfer model was developed to predict temperature profiles in the coatingsubstrate system during preheating, deposition and post-heating. For the purposes of the analysis, the coating-substrate is considered as a one-dimensional plate system as the thicknesses of the coating and the substrate are very small compare to the length and width of the steel plate. Both coating and substrate are treated as opaque to thermal radiation. The heat transfer includes the heat flux $\left(\Phi_{\mathrm{q}}\right)$ to the system from infrared radiation and flame scanning as well as convection and radiant heat exchange of the system with the environment as illustrated in Figure 3.

The equations that control the transient heat transfer at various positions are:

$$
\begin{aligned}
& \Phi_{q}-H_{c}\left(T-T_{e}\right)-\sigma \varepsilon\left(T^{4}-T_{e}^{4}\right)-\left(-k_{c} \frac{\partial T}{\partial z}\right)=0 \quad(\mathrm{z}=0, \text { at coating surface }) \\
& \frac{\partial T_{c}}{\partial t}=\alpha_{c} \frac{\partial^{2} T_{c}}{\partial z^{2}} \quad(0<\mathrm{z}<\delta \mathrm{c}, \text { within the coating }) \\
& \frac{\partial T_{s}}{\partial t}=\alpha_{s} \frac{\partial^{2} T_{s}}{\partial z^{2}} \quad(\delta \mathrm{c}<\mathrm{z}<\delta \mathrm{c}+\delta \mathrm{s} \text { within the substrate }) \\
& T_{c}\left(\delta_{c}\right)=T_{s}\left(\delta_{c}\right)(\mathrm{z}=\delta \mathrm{c}, \text { at the coating-substrate interface }) \\
& -H_{s}\left(T-T_{e}\right)-\sigma \varepsilon\left(T^{4}-T_{e}^{4}\right)-\left(-k_{s} \frac{\partial T}{\partial z}\right)=0(\mathrm{z}=\delta \mathrm{c}+\delta \mathrm{s}, \text { at back of substrate })
\end{aligned}
$$




$$
\alpha=\frac{k}{\rho c_{p}}
$$

where $T$ is the temperature at a distance $\mathrm{z}$ from the coating surface, $\mathrm{t}$ the time. $\mathrm{T}_{\mathrm{e}}$ is the ambient temperature which is fixed at $300 \mathrm{~K}$ for the simulation. $H, \sigma$ and $\varepsilon$ are convection heat transfer coefficient, Boltzmann constant and emissivity respectively. $\alpha, k, \rho$ and $\mathrm{C}_{\mathrm{p}}$ are thermal diffusivity, thermal conductivity, density and the specific heat capacity of the materials respectively. Subscript $c$ and $s$ refer to coating and substrate respectively.

Solidworks was used to build the model. A plate was chosen as a geometrical model. Only heat transfer along the direction of the plate thickness was considered. Cosmosworks was used to carry out a Finite Element Method (FEM) analysis and to provide numerical solutions of the heat transfer equations. Static analysis can give equilibrium temperature field results whereas transient analysis provides the temperature changes with time: both techniques were used in the simulation. For the transient analysis, the initial temperatures (temperature at $t=$ 0 ) of the coating and substrate system were varied in different cases in order to study their effect on the temperature distribution of the coating/substrate system.

Cosmosworks formulates the equations (1-5) governing the behaviour of each element in the mesh. The equations relate the response of the system to known material properties, restraints (e.g. heat generation) and loads (e.g. heat flux). The programme organizes the equations into a large set of simultaneous algebraic equations and solves them for the unknowns (e.g temperature). The programme estimates a global element size for the model, taking into consideration its volume, surface area and other geometric details. The size of the generated mesh (number of nodes and elements) depends on the geometry and dimensions of the model, element size, mesh tolerance, mesh control and contact specifications. The mesh size is adjustable depending on the balance between speed of analysis and accuracy. Three separate zones (coating, coating-substrate interface and substrate) were used in the meshing study. Constant fine grades were used in the coating and interface zone. To reduce the total number of cells for the simulation, grade design was taken in the substrate to produce fine cells near to the interface and coarse cells at a significant distance from the interface. Grade independent studies were carried out to ensure the simulation results were converging and this showed that when the size of the cell in the coating is smaller than $10 \%$ of the coating thickness, the result is grade independent.

The variants included coating thickness, substrate thickness, heat flux, convection coefficients and initial temperatures, and these were incorporated into the calculations. For example, the effect of coating thickness on temperature gradient can be studied by using coating thickness as a variable, which enables the programme to generate results and graphical data to enrich the overall analysis.

The physical and thermal properties of the materials used in the simulation were considered as constant as given in Table I. Environmental parameters include the environment temperature $T_{e}$ and convection coefficient $h_{c}$ and $h_{s}$ (Figure 3 ). $T_{e}$ was taken to be the ambient temperature of $300 \mathrm{~K}$. Convection was assumed to be uniformly distributed over all surfaces and equal to free convection in air; a value of $10 \mathrm{~W} /\left(\mathrm{m}^{2} / \mathrm{K}\right)$ is used as both $h_{c}$ and $h_{s}$ in the heat transfer calculations. Surface emissivity used in the simulation was 0.95 for coating $\varepsilon_{\mathrm{c}}$ and 0.6 for substrate $\varepsilon_{\mathrm{s}}$. 


\subsection{Thermal history during deposition}

The temperature-time profile of a typical thermal spray cycle was first determined. An epoxy coating was deposited on a cold steel substrate of $150 \mathrm{~mm} \times 100 \mathrm{~mm} \times 3 \mathrm{~mm}$ and the temperatures at the deposit surface and the deposit-substrate interface were recorded in-situ. Figure 4 shows the real-time temperature history of the epoxy sample during deposition and subsequently cooling. The process is cyclic in nature with large temperature fluctuations.

As the deposition proceeds by the flame torch scanning over the surface (following the pattern described in Figure 1), at a fixed position, the temperature of the coating/substrate system increases due to the energy input from the in-coming hot epoxy droplets and the flame jet. The temperature fluctuates with the movement of the torch during deposition with the surface temperature, in particular, changing dramatically during deposition. The temperaturemeasuring point, which corresponds to Point 3 in Figure 2, reaches its peak $\left(169^{\circ} \mathrm{C}\right)$ when the flame is directly above it. The interface temperature $\left(66^{\circ} \mathrm{C}\right)$ is, however, much lower during deposition. The temperature at the coating-substrate interface is observed to be higher than that at the surface during the cooling period due to convection heat loss from the coating surface to the environment. Figure 4 indicates that there is a large temperature gradient between the coating surface and coating-substrate interface during deposition. This is expected in the deposition of polymers owing to their low thermal conductivity.

The temperature distribution across the entire coating-substrate interface area (the total area of the substrate being sprayed) during deposition was also investigated. Temperatures at selected points of the interface (Figure 2) were collected together and simulated using OriginPro ${ }^{\circledR}$ and SigmaPlot ${ }^{\circledR}$ to establish the transient temperature variation with time of the entire coating-substrate interface area. Figure 5 presents six snapshots illustrating the temperature profile of the interface at a series of instants of time during the spray process (data from Figure 4). The time interval between each snapshot is 6 seconds. The sequence of the snapshots follows the movement of the torch starting from the bottom left in Figure 1 and moving from left to the far right of the first pass or row, then back from right to left, followed by left to right and so on until the entire sheet is covered. The temperature differences were translated to corresponding colour changes: red (code 1) the highest temperature and blue (code 2) the lowest. The positional change of the red hot-spot region is directly due to the movement of the flame and the shifting patterns reflect the transient nature of the spraydeposition process.

The temperature profiles of polymer coatings during deposition and cooling depend greatly upon the processing conditions and substrate geometry $[18,19]$. For example, the temperature of the deposit is expected to be increased substantially by increasing the flame power [17]. However, the inevitably high surface temperatures and temperature gradients caused by the low thermal conductivities of polymers limits this approach because it risks the degradation of the polymers at the surface [16] and under-cure at the interface. Moreover, inspection of the experimental data presented in Figures 4 indicates such short cumulative time above the curing temperature (as compared with a typical conventional curing cycle of $180^{\circ} \mathrm{C}$ for 20 minutes) that obtaining a satisfactory cure appears to be very unlikely and this was confirmed by experimental trials. A possible way to achieve sufficient curing would be to provide additional thermal energy by post-deposition heating by, for example, flame scanning or infrared irradiation of the polymer surface after deposition. In this investigation, it was decided to use the latter method as it was likely to be the more controllable. Infrared has the additional potential of smoothening out the effect of the high-temperature spikes and 
gradients during deposition as shown in Figure 4 and provides additional degrees of freedom in process control.

\section{MODEL VALIDATION AND PROCESS SIMULATION}

\subsection{Integrated coating process}

The coating process can be divided into the following stages: (i) pre-heating of the substrate; (ii) deposition of the coating material on the substrate; (iii) post-heating after the completion of deposition; (iv) cooling down to room temperature. Deposition in Stage (ii) has already been considered in the previous section and the following simulations concern the other three stages.

\subsection{Heating of the bare substrate (preheating)}

The heating of substrates of various thicknesses by infrared irradiation with heat fluxes in the range of $5 \mathrm{~W} / \mathrm{m}^{2}$ to $100 \mathrm{~kW} / \mathrm{m}^{2}$ on the side to be coated was simulated using the software and models described in Section 3. The initial temperature was set at $300 \mathrm{~K}$.

Figure 6 gives the calculated results of the temperature profiles on both sides of a $5 \mathrm{~mm}$-thick steel plate subjected to a $5 \mathrm{~kW} / \mathrm{m}^{2}$ heat flux at one side. The temperature increases rapidly at the beginning but then the rate slows down gradually. The temperature curves for the surface and the back are similar indicating a small temperature gradient inside the substrate as expected owing to the high thermal conductivity of steel. Figure 6 shows that it takes approximately $3000 \mathrm{~s}$ for the substrate to reach to an equilibrium temperature of $170^{\circ} \mathrm{C}$, after which a dynamic balance is established between the heat input to the system and the heat loss to the environment. The equilibrium temperature and the time taken to reach it are useful practical indicators. Table II gives their values for various heat fluxes: the equilibrium temperature increases with input heating power while the time-to-reach-temperature reduces. The time to reach $200^{\circ} \mathrm{C}$ is chosen in Table II, because it is a typical curing temperature. The equilibrium temperature has practical implications for the choice of heating equipment and energy expenditure, whereas the time-to-reach-temperature also relates to product throughput.

The same analysis was also applied on substrates of thicknesses of $1 \mathrm{~mm}, 3 \mathrm{~mm}, 5 \mathrm{~mm}$ and $10 \mathrm{~mm}$. The results are given in Figure 7 and show a linear relationship between substrate thickness and the heating time required to reach the targeted $200^{\circ} \mathrm{C}$. Under the same input power, it takes 10 times longer to heat a $10 \mathrm{~mm}$ substrate to the target temperature of $200^{\circ} \mathrm{C}$ compared with that required for $1 \mathrm{~mm}$ substrate. As a result, ten times as much energy is required for a $10 \mathrm{~mm}$ substrate to reach the curing temperature than a $1 \mathrm{~mm}$ substrate. This may be considered conceptually as the substrate acting as heat sink due to its large thermal mass relative to the coating. The thickness of a metal substrate or the part to be coated is therefore a practically important variable in curing thermoset coatings due to the heat sink effect and, for heavy sections, can substantially increase energy consumption.

For the purposes of validating the simulation, an experimental trial was carried out to determine temperature profiles and compare them with the theoretically calculated results. A grit-blasted steel substrate in the form of a plate of dimensions $150 \mathrm{~mm} \times 100 \mathrm{~mm} \times 10 \mathrm{~mm}$ was positioned at a distance of $100 \mathrm{~mm}$ normal to the IR heater. The heater was built with two Phillip 51011C lamps with $1871 \mathrm{~K}$ colour temperature, which provided a theoretical heat flux of $50 \mathrm{~kW} / \mathrm{m}^{2}$ and an effective heat flux of $40 \mathrm{~kW} / \mathrm{m}^{2}$. The experimentally measured 
temperature-time relationship is given in Figure 8 and shows that the time to reach $200^{\circ} \mathrm{C}$ is 190 seconds. This is close to the calculated time of 180 seconds in Figure 7 (shown by a circular black dot), which supports the simulative model.

The above FEM analysis indicates that high infrared power is required to shorten the time of substrate preheating. It takes less than a minute to preheat a $10 \mathrm{~mm}$ substrate to $200^{\circ} \mathrm{C}$ if the substrate surface is irradiated with a $100 \mathrm{~kW} / \mathrm{m}^{2}$ heat flux. An infrared heater can therefore be employed in preheating: the required power of the heater can be calculated using the heater's heat-flux field model providing the reflectance of the substrate, the target temperature and the designed time to reach the target temperature are known.

\subsection{Heating of the coated substrate (post-heating)}

The coating temperature after deposition can be controlled by using an additional heat source, such as infrared radiation. Post-deposition heating is now explored as a way to accelerate the crosslinking reaction in the coating without causing decomposition. It provides a controllable energy input to the as-deposited coating that maintains its temperature until the coating is cured and develops the required properties. In this section, the temperature gradients inside the coating and substrate during post-deposition heating are investigated. A coating-substrate system of $0.5 \mathrm{~mm}$ epoxy coating on $10 \mathrm{~mm}$ steel substrate is used in the simulation. The initial temperature for coating and substrate was set at room temperature $(300 \mathrm{~K})$.

Figure 9 shows the simulated temperature gradients in a coating-substrate system after the coating surface is heated by a $100 \mathrm{~kW} / \mathrm{m}^{2}$ heat flux for 40 seconds and 50 seconds. The calculated temperatures at the coating surface, interface and back surface of substrate are 194, 141 and $131^{\circ} \mathrm{C}$ respectively after 40 seconds. The corresponding temperatures after $50 \mathrm{~s}$ are 220,168 and $157^{\circ} \mathrm{C}$ respectively. It is seen that the 10 seconds extra heating time raised the system temperature by $26^{\circ} \mathrm{C}$.

A fundamentally significant result in Figure 9 is that the temperature gradient within the coating is two orders of magnitude higher than that in the substrate: $100^{\circ} \mathrm{C} / \mathrm{mm}$ compared with $1{ }^{\circ} \mathrm{C} / \mathrm{mm}$ respectively. There is, therefore, a large temperature gap $\left(52^{\circ} \mathrm{C}\right)$ between the coating surface and coating-substrate interface. An important practical consequence of this is that when the coating surface reaches the crosslinking temperature, the interface will be at a much lower temperature and be uncured. These large-scale differences are due to differences in the thermal conductivity, specific heat and density between the steel substrate and epoxy (Table I).

Figure 10 shows the calculated temperatures at the coating surface, coating-substrate interface and the back of substrate as a function of heating time. $220^{\circ} \mathrm{C}$ was set as the target crosslinking temperature. This will enable the crosslinking of an epoxy coating while avoiding degradation. The results show that the coating surface reaches $220^{\circ} \mathrm{C}$ after 50 seconds, the interface temperature at this time is only $168^{\circ} \mathrm{C}$. After 70 seconds the temperature at the interface reaches $220^{\circ} \mathrm{C}$ but the surface temperature rises to $270^{\circ} \mathrm{C}$ which carries with it a significant risk of degradation of the polymer coating.

To validate the simulative model, a $500 \mu \mathrm{m}$ epoxy coating was flame sprayed on a steel substrate of $150 \mathrm{~mm} \times 100 \mathrm{~mm} \times 6 \mathrm{~mm}$ and then the coating subjected to infrared irradiance of heat flux $40 \mathrm{~kW} / \mathrm{m}^{2}$ normal to its surface. Figure 11 shows the experimentally measured temperature-time curves of at the coating surface and coating-substrate interface. The measured temperature difference between the surface and the interface is approximately $50^{\circ} \mathrm{C}$ and the temperature gradient within the coating is $100^{\circ} \mathrm{C} / \mathrm{mm}$. These results are very close to 
the calculated results shown in Figures 9 and 10, which supports the simulation model. Further calculations were carried out for the same coating-substrate system subjected to a constant $40 \mathrm{~kW} / \mathrm{m}^{2}$ heat flux over its coating surface using the simulative model and presented as dotted lines on Figure 11: the calculated heating curve and rate $\left(49^{\circ} \mathrm{C} / \mathrm{min}\right)$ at both the coating surface and interface are seen to be very similar to the experimentally measured values. However, there were differences between the experimental and calculated results in terms of the temperatures and the time to reach a surface temperature of $200^{\circ} \mathrm{C}$. It required 175 seconds according to the model but experimentally, it only took 165 seconds. The calculated surface temperature is lower than the experimental one whereas the calculated interface temperature is slightly higher than the measured value.

It should be pointed out that the major assumption made in the simulation was onedimensional heat transfer through the coating and substrate thickness (z-direction), and no heat transfer in the $\mathrm{x}$ and $\mathrm{y}$ directions were considered. The experimental measurements were carried out under very similar conditions. The coated plate was subjected to a constant IR irradiance covering its entire surface. In addition, the experimental measurements in Figure 11 were taken at a position corresponding to Point 3 in Figure 2, which is right in the middle of the plate. It is noted that this position avoids the heat-transfer complexities of the edges of the plate and this contributes to the good agreement between these results. The discrepancy between the calculated and measured interface temperatures could be caused by the position of the thermocouple. For the purposes of experimental measurement, a thermocouple was inserted through a hole from back side of the substrate to very close to the interface but still within substrate. It actually records the substrate temperature at interface side, hence gives lower readings. The delay in the response time of the thermocouple may also result in a lower reading. The surface temperature was recorded by IR thermometers and refers to the real surface temperature, which is expected to be higher than the calculated average temperature of the surface cell.

\subsection{Cooling of the coating-substrate}

After post-deposition curing, the energy input will shut down and the coating temperature will fall together with that of the substrate. However, the remaining residual thermal energy in the coating-substrate system may contribute to the curing and crosslinking process during cooling to ambient temperature. This effect was investigated below using the simulation model.

In the simulation, the initial temperature of a coating-substrate system was set as $500 \mathrm{~K}$ and the environment temperature fixed at room temperature $(300 \mathrm{~K})$. The convection and radiation heat exchange condition with environment are the same as previously applied.

Figure 12 gives the calculated temperature traces for a $500 \mu \mathrm{m}$ epoxy coating deposited on a $10 \mathrm{~mm}$ thick steel substrate. The temperature at the coating surface is lower than that at the back of the substrate. The difference is due to the surface emissivity of 0.95 and 0.6 for coating and substrate respectively, which results in the coating surface losing more heat to the environment than the steel substrate loses through radiation. The interface temperature is almost the same as that of the back of the substrate. The cooling rate again is related to substrate thickness. For example, for the same $500 \mu \mathrm{m}$ coating on a $1 \mathrm{~mm}, 5 \mathrm{~mm}$ and $10 \mathrm{~mm}$ steel substrate, the calculated cooling rates are $72^{\circ} \mathrm{C} / \mathrm{min}, 19^{\circ} \mathrm{C} / \mathrm{min}$ and $10^{\circ} \mathrm{C} / \mathrm{min}$ respectively. As shown in Figure 12, curing may continue during the cooling, particularly for coating deposited on thick substrates. This should be taken into account when designing the process conditions for curing as a means of improving energy efficiency. For instance, the 
time at the curing temperature may be reduced for coatings on thick substrates as some degree of cure or 'self-curing' will occur during cooling.

\section{APPLICATION OF THE SIMULATIVE MODEL FOR PROCESS OPTIMIZATION}

\subsection{Increasing the initial temperature}

The simulation model was used to investigate the effect of preheating the substrate by increasing the initial temperature $(\mathrm{t}=0)$ from ambient temperature $\left(27^{\circ} \mathrm{C}\right)$ to $100^{\circ} \mathrm{C}$. The aim was to raise the interface temperature into the curing range and to reduce the heating time. The results are shown in Figure 13: the gap between the surface and interface remains at $50^{\circ} \mathrm{C}$ but the time required to heat to $220^{\circ} \mathrm{C}$ becomes much shorter. It now takes 23 seconds for the surface to reach $220^{\circ} \mathrm{C}$ and 44 seconds for the interface to do so (compared with $48 \mathrm{~s}$ and $70 \mathrm{~s}$ respectively for an initial temperature of $27^{\circ} \mathrm{C}$ as shown in Figure 10). The simulation was then carried out for other heat fluxes and the results in Table III indicate that the heating time can be substantially shortened and the curing temperature reached by increasing the input heat flux and raising the initial temperature. However, the large temperature gradients within the coatings will remain and potentially may cause problems in uneven curing and residual stress. The next section (Section 5.2) will address these problems.

\subsection{Controlled heating schedules to produce uniformly cured coatings}

The previous section showed that increasing the initial temperature $(\mathrm{t}=0)$ could raise the coating into the curing range and reduce the time to the temperature. However, it could not achieve uniform curing through the thickness of the coating and had the risk of overheating. This deficiency was addressed by varying the magnitude of the heat flux throughout the heating process.

The heating schedules were designed for the coating to reach and be maintained at a target temperature. It is noted that the steep temperature gradients in polymer coatings imposes an additional restriction: the temperature may be high enough for curing at the coating surface but not at the coating-substrate interface. (In passing, it is pointed out that this complication would not occur to any significant extent in metallic coatings owing to their much higher conductivities, lower temperature gradients and less sensitivity to temperature). The target temperature was, therefore, chosen to be high enough to induce full curing in an acceptable time at the interface but low enough to avoid the risk of degradation at the coating surface. In this analysis, the target temperature was selected as $220^{\circ} \mathrm{C}$.

Two heating schedules are proposed in Figure 14 to investigate the application of the simulation model. In Case 1 , the initial temperature is taken as $100^{\circ} \mathrm{C}$ for both coating and substrate (when $\mathrm{t}=0, \mathrm{~T}_{\mathrm{c}}=\mathrm{T}_{\mathrm{s}}=100^{\circ} \mathrm{C}$ ). The ambient temperature, $\mathrm{T}_{\mathrm{e}}$, remains at $300 \mathrm{~K}\left(27^{\circ} \mathrm{C}\right.$ ). This is, for example, a commonly experienced temperature of the coating immediately after spraying and before any post-heating. The initial temperatures of the coating and substrate were set at the same temperature because when spraying ceases, the temperature difference between the coating and substrate becomes negligible, as shown in Figures 4 and 6 . The infrared heating in this case is turned on with a $100 \mathrm{~kW} / \mathrm{m}^{2}$ heat flux for 25 seconds. Figure 15 shows that this enables the coating surface to reach the target temperature of $220^{\circ} \mathrm{C}$ but the interface temperature only reaches $180^{\circ} \mathrm{C}$, which is insufficient for curing. The schedule in 
Case 1 (Figure 14) then imposes a controlled linear drop of heat flux for 45 seconds such that after a total time of 70 seconds, the heat flux is decreased to $8.4 \mathrm{~kW} / \mathrm{m}^{2}$. Importantly, the profiles in Figure 15 show that both the surface and interface temperatures continue to rise after the heat flux is reduced. The surface temperature increases by about $10^{\circ} \mathrm{C}$ to a peak at $230^{\circ} \mathrm{C}$ and then declines. More significantly, the interface temperature rises to a plateau at the target temperature of $220^{\circ} \mathrm{C}$, where it is maintained along with the surface temperature. The heat flux of $8.4 \mathrm{~kW} / \mathrm{m}^{2}$ is calculated using the model to give a heat balance at this target temperature.

This is an important result as it shows that while the coating surface temperature falls from its peak at $230^{\circ} \mathrm{C}$ (due to convection and outward radiation) the interface temperature continues to rise due to conduction from the surface layers down to the interface, driven by the steep temperature gradients. As a result, the coating throughout its entire thickness, can be kept at the target temperature of $220^{\circ} \mathrm{C}$ which is high enough to induce curing but low enough to avoid degradation. The heat flux of $8.4 \mathrm{~kW} / \mathrm{m}^{2}$ is applied to maintain a temperature of $220^{\circ} \mathrm{C}$ (as calculated) from 70 to 200 seconds in order to enable curing. The heating is stopped after a total of 200 seconds and the coating-substrate system allowed to cool down naturally. These results highlight the importance of incoming conduction from the surface layers to the coating-substrate interface, which promotes curing throughout the coating thickness.

Case 2 (Figure 14) was undertaken to explore the effect of reducing the initial temperature from $100^{\circ} \mathrm{C}$ to ambient temperature $\left(27^{\circ} \mathrm{C}\right)$. This could occur in practice in discontinuous spraying or when there is a delay between spraying and post-heating the coating. The schedule begins with a constant heating flux of $100 \mathrm{~kW} / \mathrm{m}^{2}$ for 50 seconds followed by a linear drop of heat flux for 50 seconds. At a total time of 100 seconds, the heat flux was decreased to $8.4 \mathrm{~kW} / \mathrm{m}^{2}$ and is maintained at this level for a further 100 seconds (total time of 200 seconds) at which stage the heating source was shut down and natural cooling was allowed to take place. The calculated temperature curves of the coating/substrate system in responding to the heat flux-time schedule in Case 2 are shown in Figure Error! Reference source not found.16. The major difference between the schedules is the extended time at $100 \mathrm{~kW} / \mathrm{m}^{2}$ in Case 2. This shows that the extended time more than compensates for the higher initial temperature applied in Case 1. However, the surface temperature in Case 2 is higher than that in Case 1: it rises to $244^{\circ} \mathrm{C}$ before falling back to $220^{\circ} \mathrm{C}$. This runs the risk of overheating and degradation of the surface of the coating. These results emphasize the importance of accurate process control in thermally spraying thermoset coatings.

Finally, it is noted that a significant degree of curing may occur during cooling (self curing) depending upon the conditions, which has the benefit of allowing a reduction in the curing time at the top curing temperature and this should be taken into accounted in the design of the heating schedules.

It can be concluded that the use of the computer model developed in this study can provide heat flux control that will reduce temperature gradients and enable the production of uniformly cured thermoset coatings. The model shows that the entire through-thickness coating can be cured without the risk of surface overheating by utilizing inward conduction from the outer layers. The results indicate that effects such as self-curing can be employed to raise the energy efficiency. In conclusion, the research shows that thermosets can be successfully deposited by thermal spraying provided sufficiently accurate process control is applied. 


\section{CONCLUSIONS}

- A computer model has been developed that simulates the deposition of thermoset coatings on metal substrates using thermal spraying and high-energy infrared irradiation.

- The model uses readily-available commercial software to simulate the effect of process parameters and coating/substrate geometries.

- The model was validated and applied to demonstrate how it could enable precise control of the coating process as well as improve energy efficiency and coating quality.

- An adequately cured thermoset coating could not be deposited by conventional thermal spraying owing to insufficient cumulative time above the cure temperature. Preheating and post-heating under a constant heat source are shown to provide more time above the curing temperature but the inherent temperature gradients led to nonuniform curing, residual stress and the risk of overheating.

- Further research showed that uneven curing and overheating could be overcome by using variable heat fluxes during the coating process.

- The model shows that the entire through-thickness coating can be cured without the risk of surface overheating by controlled utilization of inward conduction from the outer layers.

- The thickness of the metal substrate is an important variable as it acts as a heat sink and, for heavy sections, can substantially increase the energy consumption.

- Curing continues during cooling giving rise to self-curing, which can reduce the time and energy needed at the curing temperature.

- The results provide a methodology for the thermal-spray deposition of thermoset coatings and indicate the need for sufficiently accurate process control.

\section{Acknowledgements}

The authors wish to thank Innovate UK for funding the project and Akzo Nobel Coatings Ltd for collaboration and providing feedstock powders. We would also like to thank Philips Electronics Ltd and Network Rail Ltd for their collaboration in the project.

\section{References}

1. Plastic flame spraying, Industrial Paint \& Powder, v 70, 1994, n 6, June, pp.31-32.

2. H. Breuer, A. Jerz, Erweiterung der Anwendungsbereiche des KunststoffpulverFlammspritzens. Diploma thesis Fachhochschule Niederrhein, Krefeld, Germany, 1997

3. D. Richart, Resins for thermosetting powder coatings, Industrial Paint \& Powder, Dec 2000.

4. Z.W.Wicks, et al, Organic coatings: science and technology, 3rd edition, WileyInterscience, 2007, p.550

5. Y. Bao, D.T. Gawne, "Plasma spray deposition of nylon 11 coatings", Trans. Inst. Metal Finishing, 69 (1991) 152-157. 
6. S.P. Tambe, S.K. Singh, M. Patri and D. Kumar, "Ethylene vinyl acetate and ethylene vinyl alcohol copolymer for thermal spray coating application", Progress in Organic Coatings, 62 (2008) 382-386.

7. S.K. Singh, S.P. Tambe, V.S. Raja and D. Kumar, "Thermally sprayable polyethylene coatings for marine environment”, Progress in Organic Coatings, 60 (2007) 186-193.

8. T.Zhang, D.T.Gawne and Y.Bao, "Plasma sprayed PMMA coatings on steel", Trans. Inst. Metal Finish., 76 (1998) 183-186.

9. E. Leivo, T. Wilenius, T. Kinos, P. Vuoristo, and T. Mäntylä, "Properties of thermally sprayed fluoropolymer PVDF, ECTFE, PFA and FEP coatings", Progress in Organic Coatings, 49 (2004) 69-73.

10. D.T. Gawne, "Thermal spraying of polymer coatings", in "Surface Engineering Vol. III: Process Technology and Surface Analysis", Editors P.K. Datta and J.S. Gray, Royal Society of Chemistry, Cambridge, (1993) 141-162.

11. C. Zhang, G. Zhang, V. JI, H. Liao, S. Costil, and C. Coddet, "Microstructure and mechanical properties of flame-sprayed PEEK coating remelted by laser process", Progress in Organic Coatings, 66 (2009) 248-253.

12. Y. Bao, D.T. Gawne and T. Zhang, "The effect of feedstock particle size on the heat transfer rates and properties of thermally sprayed polymer coatings", Trans. Inst. Metal Finishing, 73 (1995) 119-124.

13. Y. Bao and D.T. Gawne, "Processing and characterization of glass-filled polyamide composite coatings", J. Mater. Sci., 29 (1994) 1051-1055.

14. Y. Bao, D.T. Gawne, D. Vesely and M.J. Bevis, "Production of polymer matrix composite coatings by thermal spraying", Trans. Inst. Metal Finishing, 72 (1994) 110113.

15. Y. Bao and D.T. Gawne, "Plasma spray deposition and engineering applications of magnesium hydroxide-polyamide composite coatings", Trans. Inst. Metal Finishing, 75 (1997) 189-193.

16. T.Zhang, D.T.Gawne and Y.Bao, "Influence of process parameters on the degradation of thermally sprayed polymer coatings", Surface and Coatings Technology, 96 (1997) 337-344.

17. B.Liu, T.Zhang and D.T.Gawne, "Computational analysis of the influence of process parameters on the flow field of a plasma jet", Surface and Coatings Technology, 132 (2000) 202-216.

18. D.T.Gawne, B.Liu and T.Zhang, "Computational analysis of the influence of a substrate, solid shield and gas shroud on the flow field of a plasma jet", Surface and Coatings Technology, 153 (2002) pp138-147.

19. T. Zhang, Y. Bao and D.T. Gawne and P. Mason "Effect of a moving flame on the temperature of polymer coatings and substrates", Progress in Organic Coatings 70 (2011) 45-51.

20. W. Xia, H. Zhang, G. Wang, and Y. Yang, "A novel integrated temperature investigation approach of sprayed coatings during APS process," Journal of Materials Processing Technology, 209 (2009) 2897-2906. 
21. M.S.A. Bakar, P. Cheang and K.A. Khor, "Thermal processing of hydroxyapatite reinforced polyetheretherketone composites", Journal of Materials Processing Technology, 89-90 (1999) 462-466.

22. W.D. Callister, D.G. Rethwiisch, Materials Science and Engineering, 8th Edition, 2011, Wiley, NJ, Appendix B.

23. D.W. van Krevelen, K.te Nijenhuis, "Properties of Polymers", 4th Edition, 2009, Elsevier, Amsterdam. 
Table I Properties of the materials [22,23]

\begin{tabular}{|l|l|l|l|}
\hline & $\begin{array}{l}\text { Steel } \\
(\text { substrate })\end{array}$ & $\begin{array}{l}\text { Polyester } \\
(\text { coating })\end{array}$ & $\begin{array}{l}\text { Epoxy } \\
(\text { coating })\end{array}$ \\
\hline Density, $\rho\left(\mathrm{kg} \mathrm{m}^{-3}\right)$ & 7800 & 1600 & 1800 \\
\hline Thermal conductivity k $\left(\mathrm{Wm}^{-1} \mathrm{~K}^{-1}\right)$ & 43 & 0.17 & 0.19 \\
\hline Specific heat $\mathrm{C}_{\mathrm{p}} \mathrm{J} \mathrm{kg}^{-1} \mathrm{~K}^{-1}$ & 440 & 920 & 1050 \\
\hline Curing schedule @ $200^{\circ} \mathrm{C}$ (Minutes) & & 10 & 8 \\
\hline
\end{tabular}

Table II. Calculated effect of heating power on heating time for a $5 \mathrm{~mm}$ thick steel substrate.

\begin{tabular}{|c|c|c|}
\hline $\begin{array}{c}\text { Heat flux } \\
\left(\mathrm{kW} / \mathrm{m}^{2}\right)\end{array}$ & $\begin{array}{c}\text { Equilibrium } \\
\text { temperature }\left({ }^{\circ} \mathrm{C}\right)\end{array}$ & $\begin{array}{c}\text { Time to reach } 200^{\circ} \mathrm{C} \\
(\mathrm{s})\end{array}$ \\
\hline 5 & 171 & $\infty$ \\
\hline 6 & 193 & $\infty$ \\
\hline 7 & 213 & 1042 \\
\hline 8 & 232 & 704 \\
\hline 9 & 250 & 555 \\
\hline 10 & 267 & 460 \\
\hline
\end{tabular}

Table III Calculated time required to reach $220^{\circ} \mathrm{C}$ at surface and at interface from an initial temperature of $100^{\circ} \mathrm{C}$ under various heat fluxes

\begin{tabular}{|c|c|c|c|c|c|c|}
\hline Heat flux $\left(\mathrm{kW} / \mathrm{m}^{2}\right)$ & 9 & 10 & 20 & 50 & 80 & 100 \\
\hline $\begin{array}{c}\text { Time (s) for surface temperature } \\
\text { to rise from } 100 \text { to } 220^{\circ} \mathrm{C}\end{array}$ & 1680 & 1071 & 274 & 74 & 35 & 23 \\
\hline $\begin{array}{c}\text { Time }(\mathrm{s}) \text { for interface temperature } \\
\text { to rise from } 100 \text { to } 220^{\circ} \mathrm{C}\end{array}$ & 1825 & 1140 & 300 & 95 & 56 & 44 \\
\hline
\end{tabular}




\section{FIGURES}

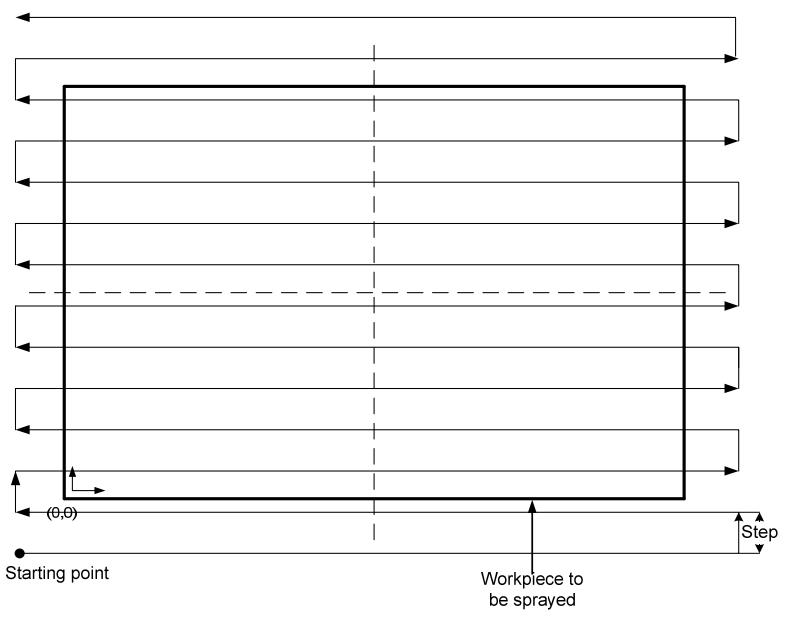

Figure 1. Schematic of spray-torch movement over a rectangular substrate

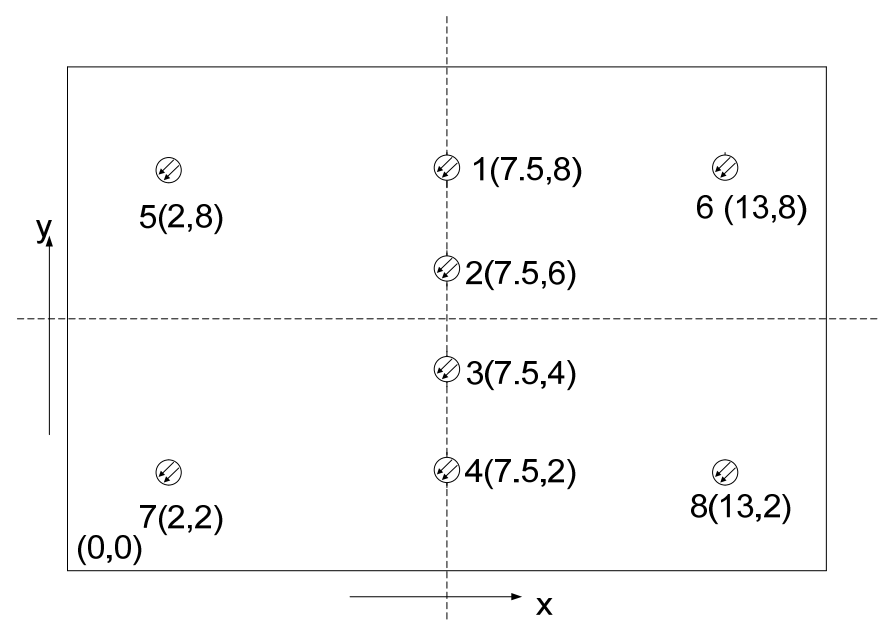

Figure 2. Positional coordinates (in $\mathrm{cm}$ ) of eight thermocouples for temperature measurements on a steel substrate of dimensions $15 \mathrm{~cm}$ by $10 \mathrm{~cm}$.

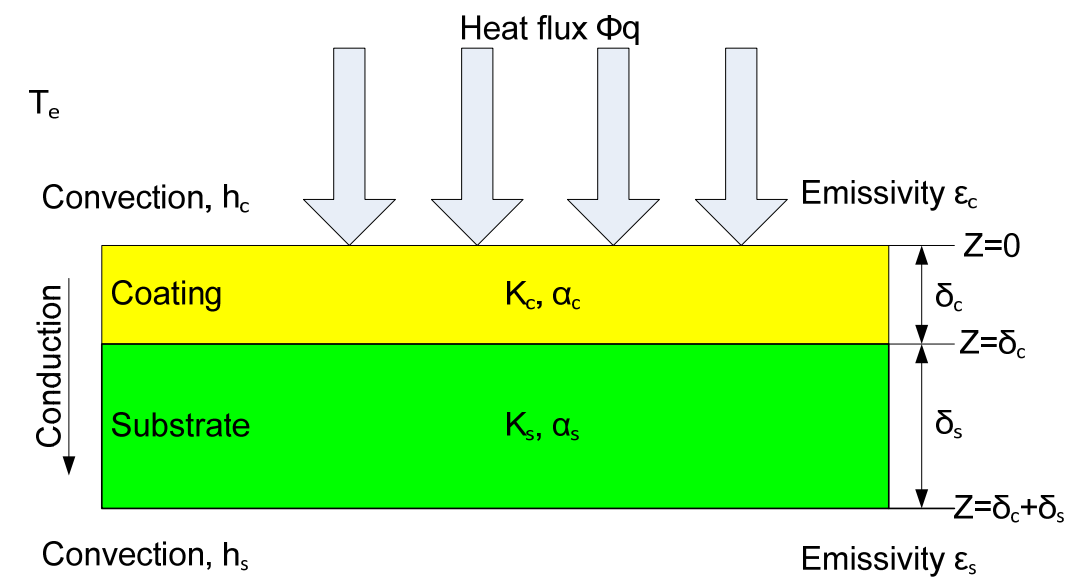

Figure 3. Schematic of coating-substrate heat transfer due to heat flux from flame and infrared radiation 


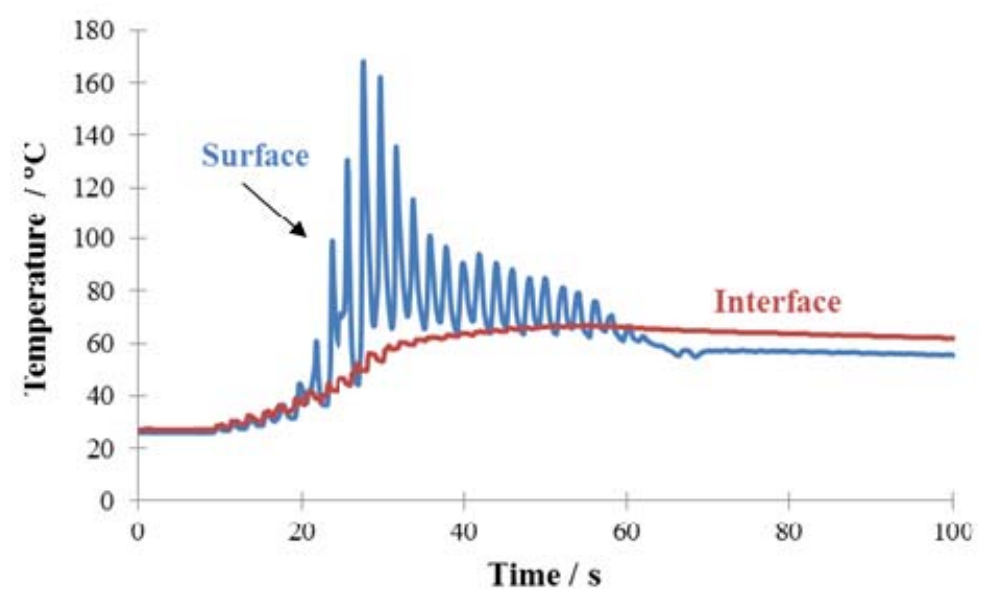

Figure 4. Experimentally measured temperature profiles of coating surface and coating-substrate interface (at point 3 in Figure 2) for epoxy powder deposition on $3 \mathrm{~mm}$ steel substrate using $5 \mathrm{~kW}$ flame power.

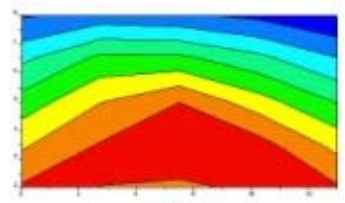

18

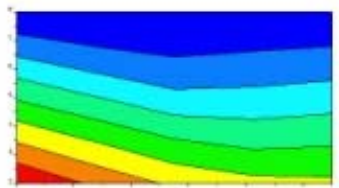

0

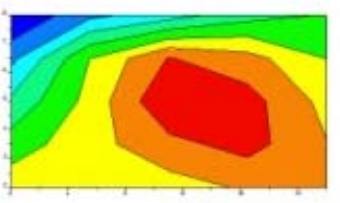

24

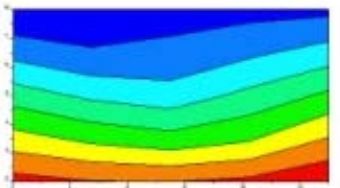

6

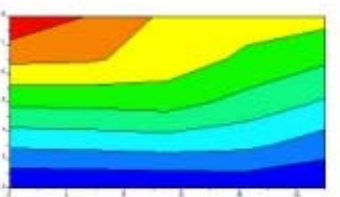

30

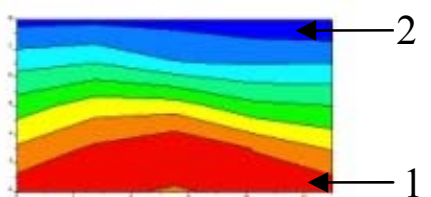

12

Figure 5. Progress of interface temperature profile during thermal spraying. Each thermal image represents a snapshot of the temperature distribution over the coating-substrate interface at various times in seconds from the start of the spraying process.

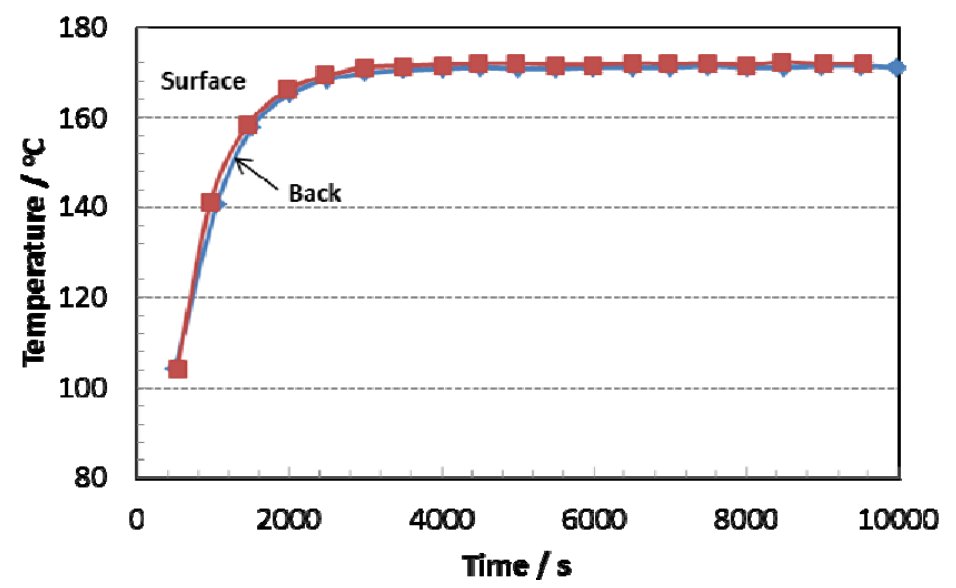

Figure 6. The calculated temperature history of a $5 \mathrm{~mm}$ thick steel substrate subjected to a heat flux of $5 \mathrm{~kW} / \mathrm{m}^{2}$. 


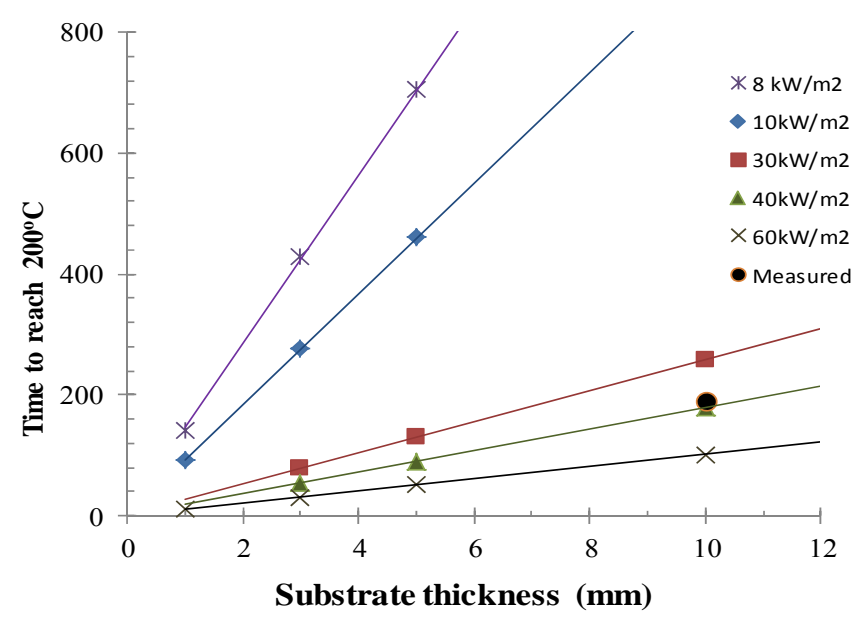

Figure 7. The effect of substrate thickness and heat flux on the calculated heating time required to reach a target temperature of $200^{\circ} \mathrm{C}$.

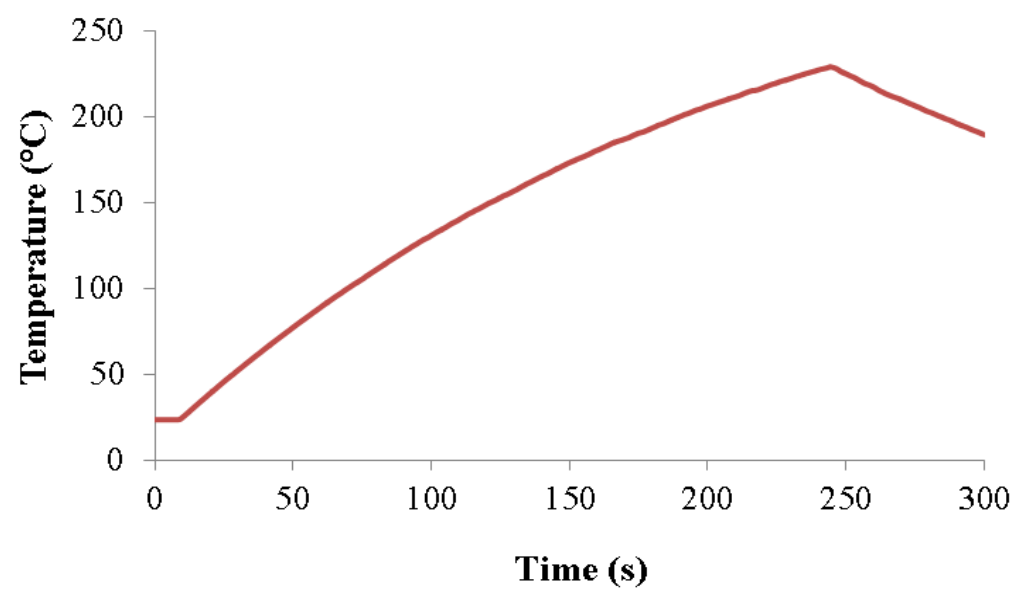

Figure 8 . The measured temperature at steel surface exposed to a $40 \mathrm{~kW} / \mathrm{m}^{2}$ infrared irradiance.

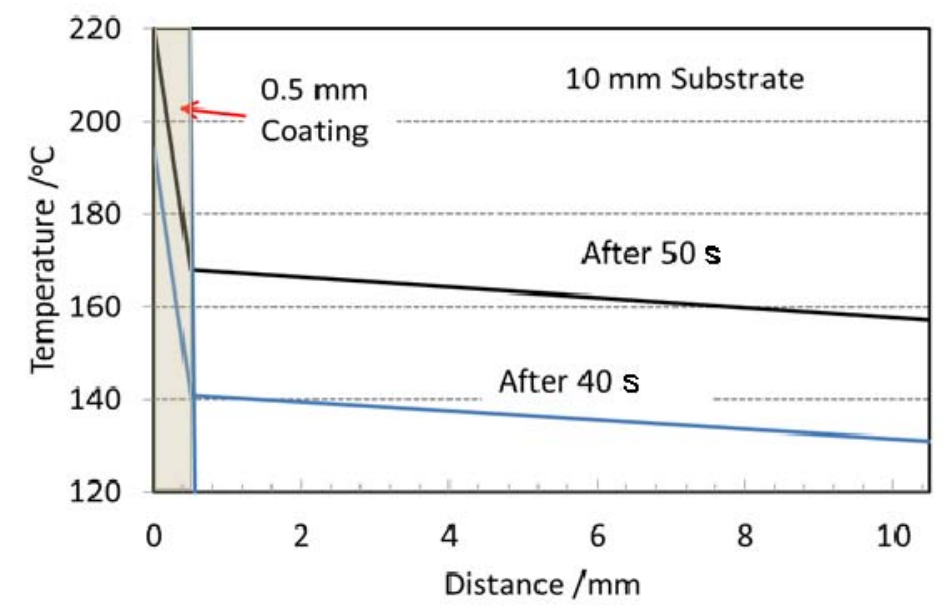

Figure 9. Calculated temperature profiles for a $500 \mu \mathrm{m}$ epoxy coating on a $10 \mathrm{~mm}$ steel substrate after $40 \mathrm{~s}$ and $50 \mathrm{~s}$ using a $100 \mathrm{~kW} / \mathrm{m}^{2}$ heat flux 


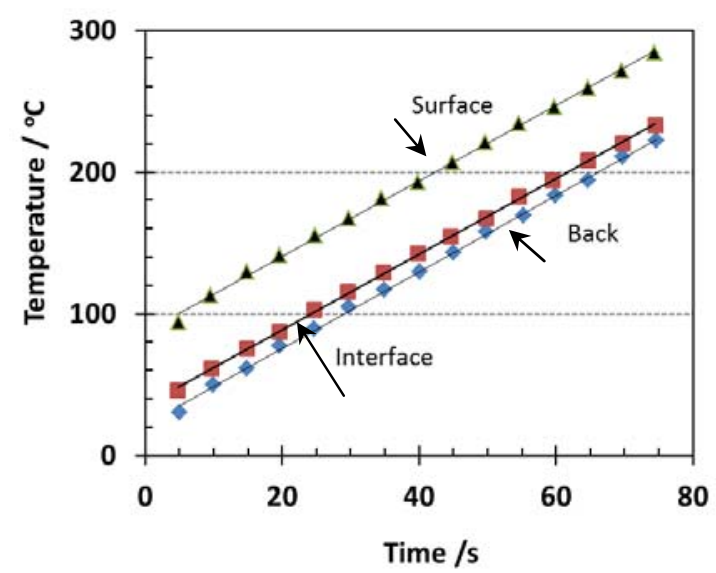

Figure 10. Calculated temperature traces at coating surface, interface and substrate back surface under $100 \mathrm{~kW} / \mathrm{m}^{2}$ heat flux.

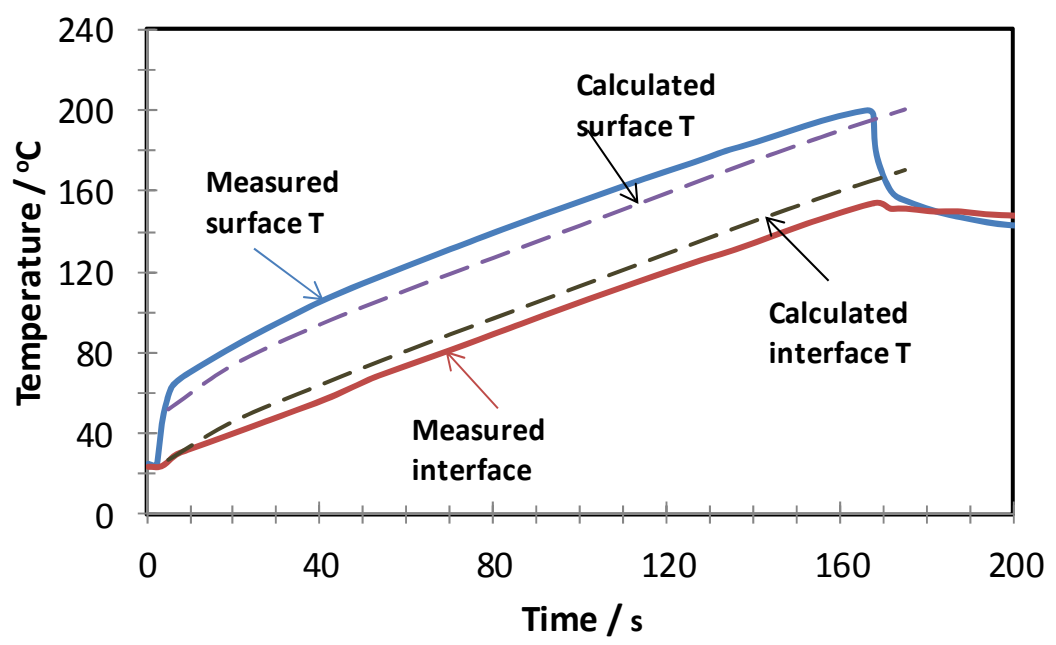

Figure 11. The experimentally measured and calculated (as shown by dotted line) temperature profiles of a $500 \mu \mathrm{m}$ epoxy coating on a $6 \mathrm{~mm}$ steel substrate subjected to a $40 \mathrm{~kW}$ infrared irradiance flux normal to its surface. 


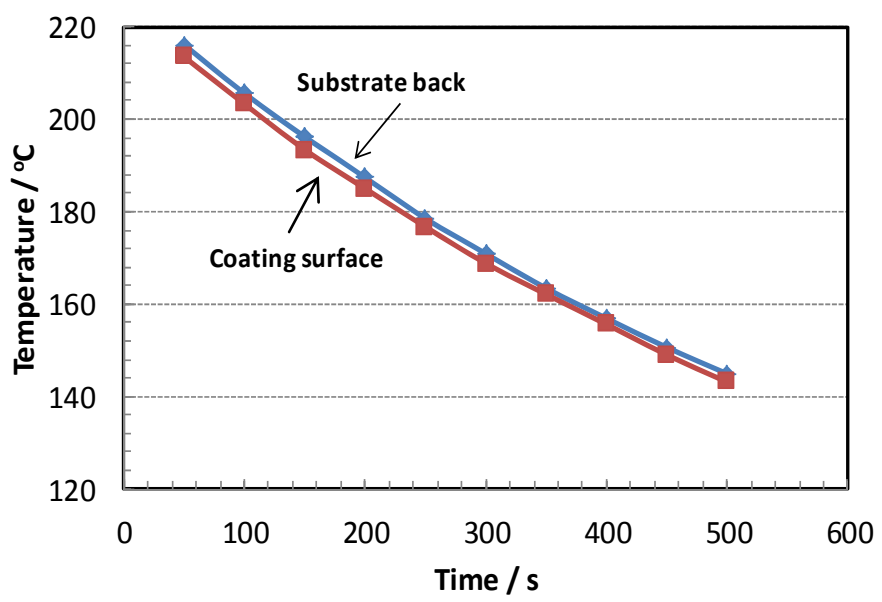

Figure 12. The calculated temperature trace of a $500 \mu \mathrm{m}$ epoxy coating on a $10 \mathrm{~mm}$ thick steel substrate cooling down from $220^{\circ} \mathrm{C}$. The bottom curve refers to the coating surface and the top curve to the back of the substrate.

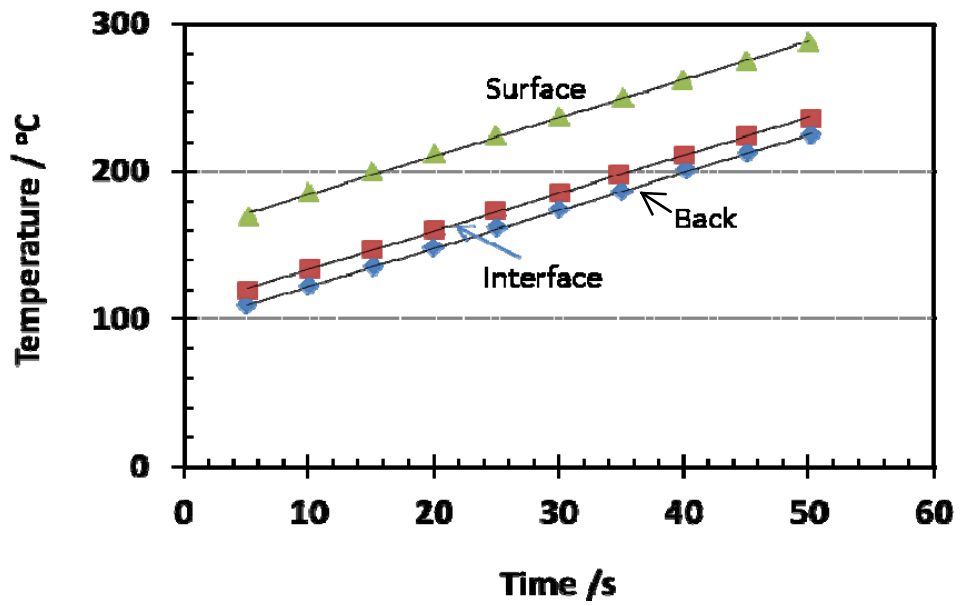

Figure 13. Calculated temperature traces at coating surface, interface and substrate back under flux.

is

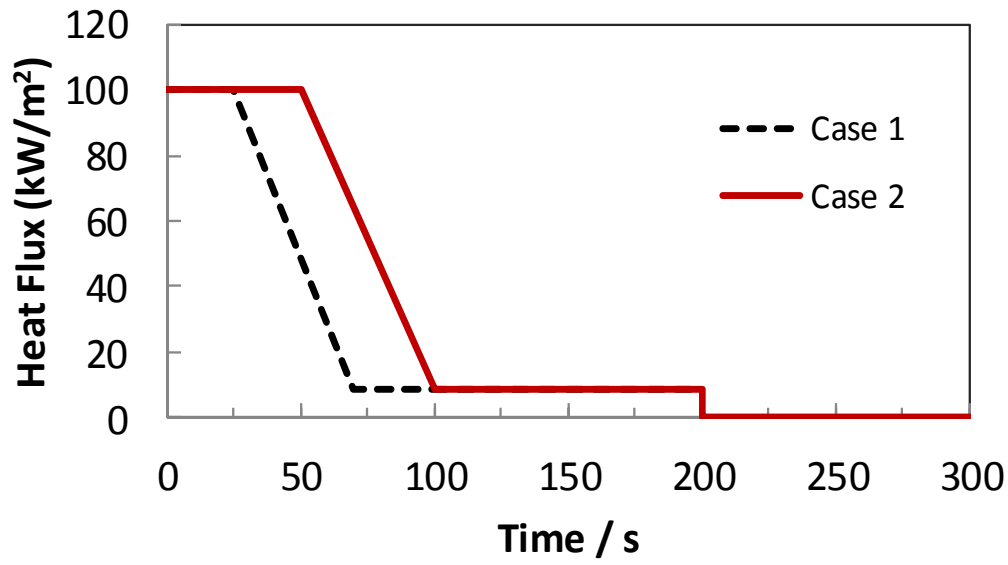
$100 \mathrm{~kW} / \mathrm{m}^{2}$ heat Initial temperature $100^{\circ} \mathrm{C}$

Figure 14. Heat-flux schedules to control the coating temperature at $220^{\circ} \mathrm{C}$ from an initial temperature of $100^{\circ} \mathrm{C}$ (Case 1) and $27^{\circ} \mathrm{C}$ (Case 2). 


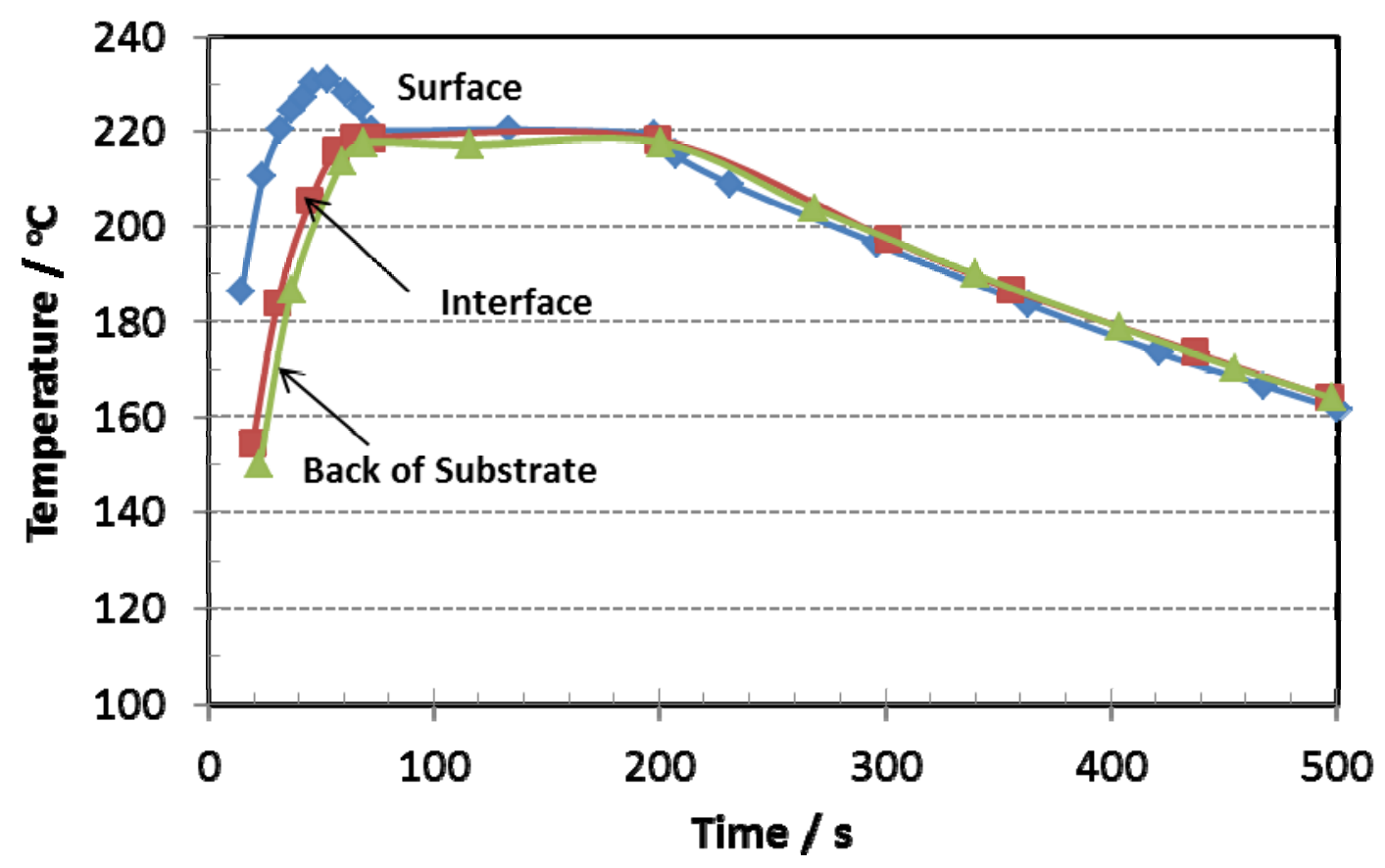

Figure 15. Calculated temperatures resulting from the Case 1 schedule in Figure 14

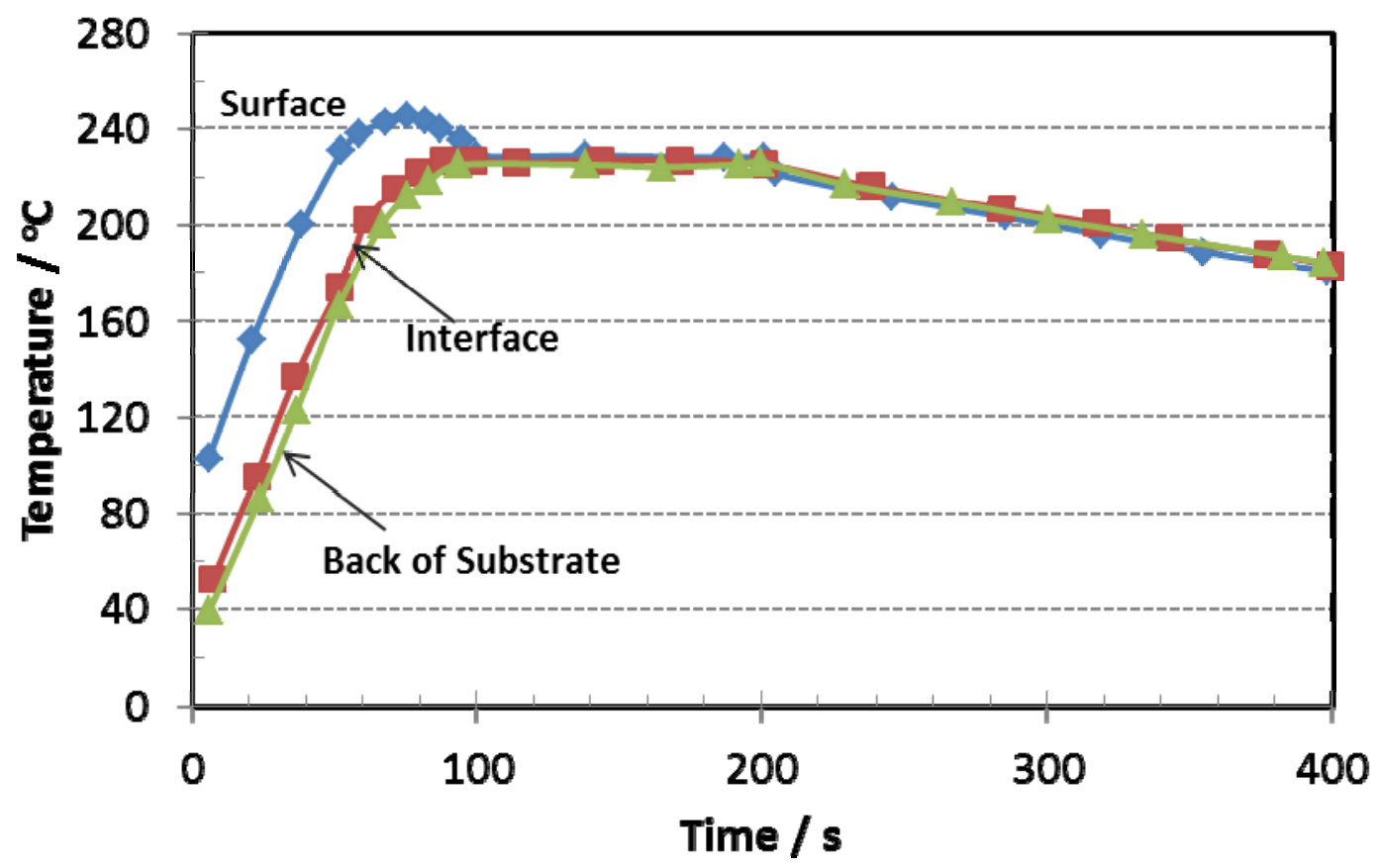

Figure 16. The calculated temperature profile of a coating-substrate system subjected to the heat flux schedule Case 2 in Figure 14. 